\title{
Implementasi Jaringan Internet Site To Site VPN Dengan Metode IPSec Pada PT Telkom Akses
}

\author{
Try Budi Septiandoko ${ }^{1}$, Desmulyati ${ }^{2}$, Andi Taufik ${ }^{3}$ \\ 1,2,3 Program Studi Teknik Informatika Sekolah Tinggi Manajemen Informatika dan Komputer Nusa Mandiri \\ J1. Jatiwaringin No. 2, Cipinang Melayu, Makasar, Jakarta Timur - 13620, Indonesia \\ e-mail : ${ }^{1}$ trybud12161041@ nusamandiri.ac.id, ${ }^{2}$ desmulyati.dmy@ nusamandiri.ac.id, \\ 3andi.iuf@nusamandiri.ac.id
}

Artikel Info : Diterima : 03-12-2020| Direvisi : 29-12-2020| Disetujui : 03-01-2020

\begin{abstract}
Abstrak - Virtual Private Network (VPN) merupakan suatu jaringan komunikasi lokal yang terhubung melalui jaringan publik, dengan private network keamanan data, ketertutupan transfer data dari akses ilegal serta skalabilitas jaringan menjadi standar utama dalam Virtual Private Network (VPN). Dalam membangun VPN pada PT. Telkom Akses dilakukan dengan metode Internet Protocol Security (IP Sec). PT Telkom Akses bergerak dalam bisnis penyediaan layanan konstruksi dan pengelolaan infrastruktur jaringan. Pada saat ini PT Telkom Akses melakukan pengiriman data-data perusahaan menggunakan email, jika menggunakan email perusahaan belum bisa memastikan keamanan data yang dikirim. PT Telkom yang memiliki banyak kantor cabang diharuskan memiliki koneksi internet yang cepat dan stabil untuk pengiriman data-data perusahaan yang bersifat rahasia. Melihat permasalahan yang ada, ada beberapa yang didapat diantaranya, komunikasi antar pengguna masih belum optimal. Pengiriman data dari kantor cabang ke kantor pusat atau sebaliknya, masih belum terenkripsi yang mengakibatkan data bisa dilihat atau diambil oleh orang yang tidak berkepentigan dan kerahasiaan perusahaan bisa terancam. Maka dibuatnya jaringan VPN dengan metode IPSEC akan mendapakan koneksi yang lebih stabil dan lebih aman, file dan folder yang dapat dipakai bersama-sama oleh anggota jaringan, memudahkan network administrator dalam mengelola jaringan jika terkendala jarak antar site serta jaringan telah terenkripsi dengan baik dan sudah menggunakan autentikasi untuk menghubungkan antar site.
\end{abstract}

Kata Kunci: Jaringan, VPN, IPSEC

Abstract - Virtual Private Network (VPN) is a local communication network that is connected through a public
network, with a private data security network, the closure of data transfer from illegal access and network
scalability are the main standards in a Virtual Private Network (VPN). In building a VPN at PT. Telkom access is
done using the Internet Protocol Security (IP Sec) method. PT Telkom Akses is engaged in the business of providing
construction services and managing network infrastructure. At this time PT Telkom Akses sent company data using
email, if using company email could not ensure the security of the data sent. PT Telkom, which has many branch
offices, is required to have a fast and stable internet connection for transmitting confidential company data.
Looking at the existing problems, there are several things that are obtained including, communication between
users is still not optimal. Data transmission from branch offices to the head office or vice versa is still not
encrypted, which means that data can be viewed or retrieved by unauthorized persons and company confidentiality
can be threatened. So creating a VPN network with the IPSEC method will get a more stable and safer connection,
files and folders that can be shared by network members, making it easier for network administrators to manage
the network if the distance between sites is constrained and the network is well encrypted and already using
authentication to connect between sites.

Keywords: Network, VPN, IPSEC

This work is licensed under a Creative Commons Attribution-ShareAlike 4.0 International License. 


\section{PENDAHULUAN}

Kebutuhan akan ketersediaan jaringan komunikasi dan internet saat ini sangat tinggi dengan meningkatnya ketergantungan manusia akan peranan Teknologi Informasi. Hal tersebut mempunyai dampak diperlukan adanya sistem penyediaan layanan internet yang efisien, handal namun tetap ekonomis dan aman. Kemajuan dalam bidang teknologi khususnya teknologi jaringan memudahkan perusahaan untuk lebih berkembang dan dapat menghadapi tantangan bisnis kedepan. (Darma et al., 2018)

PT Telkom Akses bergerak dalam bisnis penyediaan layanan konstruksi dan pengelolaan infrastruktur jaringan. Pada saat ini PT Telkom Akses melakukan pengiriman data-data perusahaan menggunakan email, jika menggunakan email perusahaan belum bisa memastikan keamanan data yang dikirim. PT Telkom yang memiliki banyak kantor cabang diharuskan memiliki koneksi internet yang cepat dan stabil untuk pengiriman data-data perusahaan yang bersifat rahasia. (Sulistyanto, 2018)

Melihat permasalahan yang ada, ada beberapa yang didapat diantaranya, komunikasi antar pengguna masih belum optimal. Pengiriman data dari kantor cabang ke kantor pusat atau sebaliknya, masih belum terenkripsi yang mengakibatkan data bisa dilihat atau diambil oleh orang yang tidak berkepentigan dan kerahasiaan perusahaan bisa terancam. (Khasanah \& Utami, 2018)

Dikarenakan permasalahan perusahaan tersebut PT Telkom Akses akan merancang suatu VPN sebagai sarana dalam komunikasi dan transfer data antar cabang secara aman, agar dapat menjaga validitas dan keamanan data dari pihak yang tidak berwenang.

\section{METODOLOGI PENELITIAN}

\section{Metode Penelitian}

Metode penelitian yang digunakan pada PT. Telkom Akses yaitu menggunakan metode action research metode tersebut menjadi beberapa tahapan penelitian yaitu melakukan diagnosa, membuat rancangan tindakan, melakukan tindakan, melakukan evaluasi. Melakukan diagnosa yang berkaitan erat dengan permasalahan yang hendak dipecahkan. Pada tahap ini dilakukan diagnosa bersama karyawan di PT. Telkom Akses dan menganalisa tentang interkoneksi jaringan berjalan antara kantor pusat dan cabang dalam bentuk topologi baik secara fisik maupun logic. Terdapat permasalahan pada jaringan internet yang kurangnya sistem keamanan jaringan sehingga mengakibatkan data bisa dilihat atau diambil oleh orang yang tidak berkepentigan dan kerahasiaan perusahaan bisa terancam. (Darma et al., 2018)

\section{Analisis Dan Kebutuhan}

Dari analisis yang dilakuan pada PT. Telkom Akses, tidak ada perubahan pada topologi jaringan yang ada hanyanya saja ada perubahan pada jaringan komunikasi antara kantor pusat dan cabang masih menggunakan keamanan jaringan VPN dengan metode PPTP Tunneling yang masih rentan terhadap pencurian data dan dapat mengganggu kestabilan akses jaringan internet, sehingga harus diubah menggunakan metode IPSEC. (Ikhwan \& Amalina, 2017)

\section{HASIL DAN PEMBAHASAN}

\section{Skema Jaringan Berjalan}

\section{a. Topologi Jaringan}

Topologi jaringan merupakan hal yang paling mendasar dalam membentuk sebuah jaringan, untuk topologi jaringan yang digunakan yaitu Topologi Tree, dimana semua peralatan antara kantor pusat dan cabang saling terhubung tanpa adanya perlindungan komunikasi. (Hutahaean dan Rohim, 2016) 


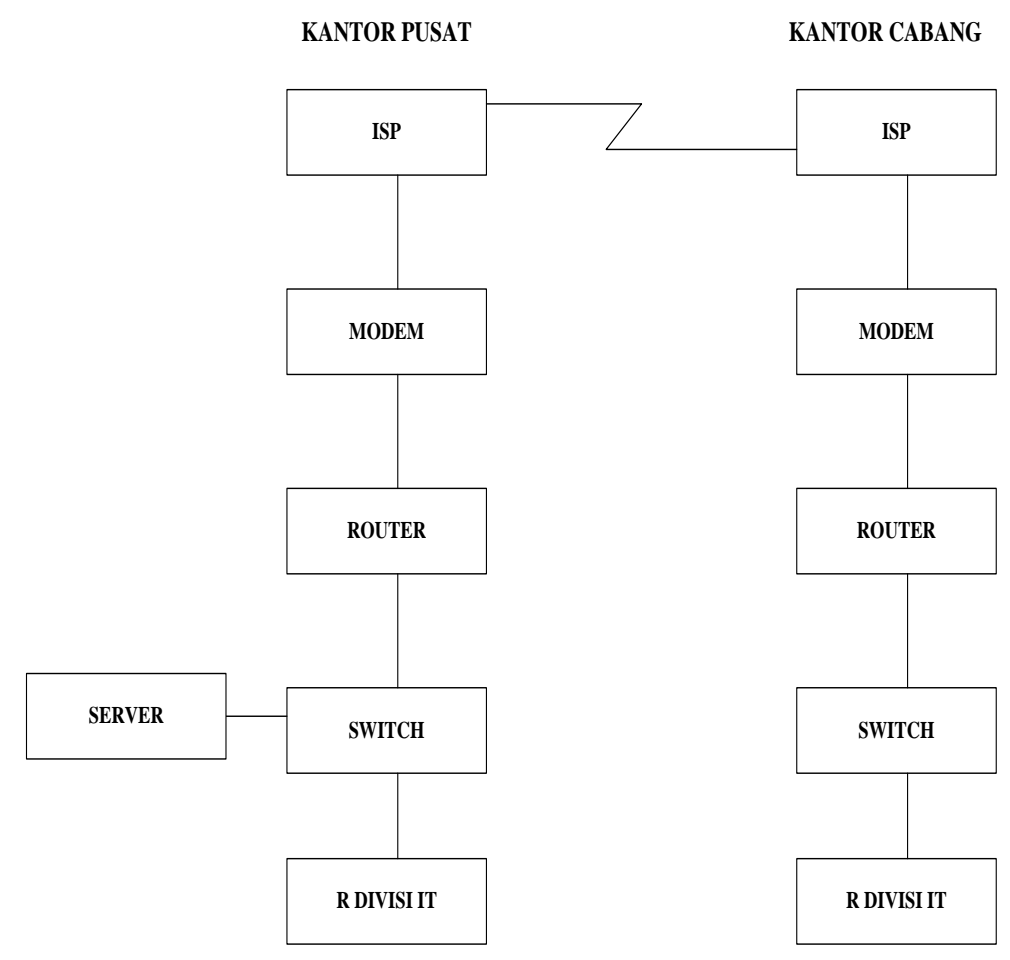

Sumber: PT. Telkom Akses (2020)

Gambar 1. Topologi Jaringan WAN PT. Telkom Akses

Dapat dikethui dari gambar 1 bahwa:

a. Di dalam jaringan PT.Telkom Akses terdapat satu buah server yang berfungsi untuk melayani, membatasi, dan mengontrol akses terhadap client-client dan sumber daya pada suatu jaringan komputer.

b. Pada jaringan tersebut terdapat Router, Pada setiap router dihubungkan kabel Fiber Optic melalui jaringan kabel didalam tanah.

c. Internet Service Provider yang digunakan adalah ISP Telkom Speedy.

d. Dalam setiap jaringan terdapat satu modem dan satu switch.

e. Dari gambar jaringan di atas Topologi yang digunakan adalah Topologi Star.

\section{b. Arsitektur Jaringan}

Arsitektur jaringan VPN yang di buat menggunakan metode PPTP yaitu protokol jaringan yang memungkinkan pengamanan transfer data dari remote client (client yang berada jauh dari server) ke server pribadi perusahaan dengan membuat sebuah VPN melalui TCP/IP. Teknologi jaringan PPTP merupakan pengembangan dari remote access Point-to-Point protocol. PPTP merupakan protokol jaringan yang merubah paket PPP menjadi IP datagram agar dapat ditransmisikan melalui internet.(Watmah, 2020) 
Tabel 1. Tabel IP Address PT. Telkom Akses

\begin{tabular}{|c|c|c|c|c|}
\hline Device & Port & IP Address & Information & Range IP \\
\hline Modem Pusat & Eth 1 & 10.134.y.z & IP Public & \\
\hline Modem Cabang & Eth 1 & 10.177.y.z & IP Public & \\
\hline \multirow{2}{*}{ Mikrotik Pusat } & Eth 1 & 10.134.y.z & IP Public & \\
\hline & Eth 2 & 10.10.10.1 & IP Static & \\
\hline \multirow{2}{*}{ Mikrotik Cabang } & Eth 1 & 10.177.y.z & IP Public & \\
\hline & Eth 2 & 192.168.20.1 & IP Static & \\
\hline LAN Pusat & Eth 2 - Eth 24 & 10.10.10.2 & IP Private Dynamic & $10.10 .10 .2-10.10 .10 .50$ \\
\hline LAN Cabang & Eth $2-$ Eth 24 & 192.168.20.2 & IP Private Dynamic & 192.168.20.2 - 192.168.20.30 \\
\hline VPN Pusat & Tunnel 1 & 172.16 .16 .1 & IP Local Address & \\
\hline VPN Cabang & Tunnel 2 & 172.16 .16 .2 & IP Remote Address & \\
\hline
\end{tabular}

Sumber: PT. Telkom Akses (2020)

\section{c. Skema Jaringan}

Pada skema jaringan yaitu sebuah sistem yang di dalamnya terdiri dari beberapa komputer dan perangkatperangkat jaringan yang dapat saling terhubung, antara satu dengan yang lainnya melalui media transmisi kabel maupun nirkabel, sehingga dapat saling berbagi (sharing) data dimana semua komunikasi antara kantor pusat dan cabang hanya menggunakan jaringan PPTP Tunneling yang rentan terhadap masalah keaaman data. (- AMIK BSI Purwokerto \& - AMIK BSI Purwokerto, 2018)

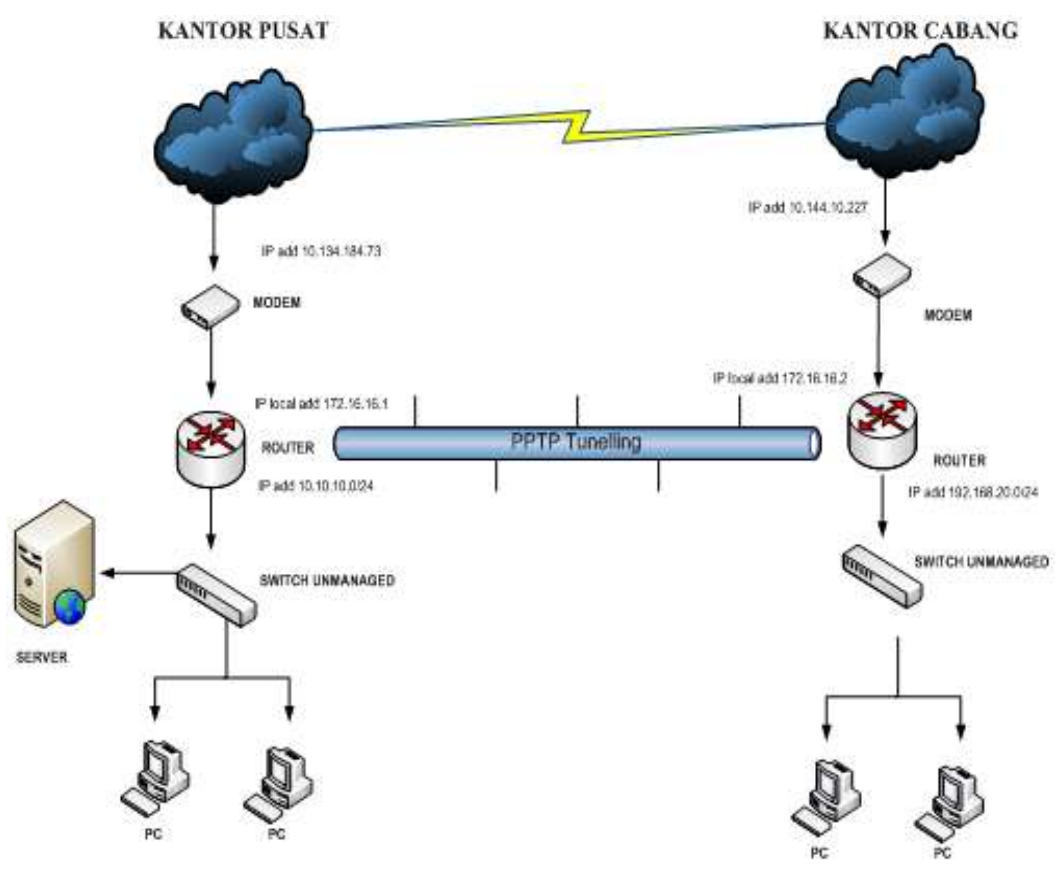

Sumber: PT. Telkom Akses (2020)

Gambar 2. Skema Jaringan PT. Telkom Akses 


\section{d. Keamanan Jaringan}

Untuk masalah Keamanan jaringan, PT. Telkom Akses mengamankan jaringan yang terhubung ke publik menggunakan fasilitas firewall mikrotik dan untuk mengamankan dari virus, antivirus yang dipakai pada server dan client mengunakan antivirus kaspersky dan smadav.(Rianto, 2018)

\section{Spesifikasi Hardware dan Software}

\subsection{Spesifikasi Hardware}

a. Personal Computer (PC)

Tabel 2. Spesifikasi Hardware Personal Computer

\begin{tabular}{ll}
\hline Needs & Information \\
\hline Monitor & Lenovo \\
Processor & Intel Core $32.0 \mathrm{Ghz}$ \\
RAM & $4 \mathrm{~GB}$ \\
VGA & Intel HD Graphics \\
Harddisk & Seagate SATA $500 \mathrm{~Gb}$ \\
Optical Drive & Lenovo DVD \\
Mouse & Logitech \\
Operating System & Windows 764 bit \\
\hline
\end{tabular}

Sumber: PT. Telkom Akses (2020)

b. Server

Tabel 3. Spesifikasi Hardware Server

\begin{tabular}{ll}
\hline Needs & Information \\
\hline Processor & Xeon 8C E5-2680 130W 2.7GHz \\
RAM & 8 GB DDR3 1333MHz \\
Harddisk & IBM 500 Gb \\
Power Supply & IBM Power Supply \\
Optical Drive & IBM Ultra Slim SATA DVD-ROM \\
Monitor & LCD 17 Inch \\
\hline
\end{tabular}

Sumber: PT. Telkom Akses (2020)

c. Router

Tabel 4. Spesifikasi Hardware Router

\begin{tabular}{ll}
\hline Needs & Information \\
\hline Manufacturer & Mikrotik Router OS RB 750G \\
RAM & $64 \mathrm{MB}$ \\
Memory & $32 \mathrm{MB}$ DDR SDRAM \\
Operating System & Mikrotik Router OS v3, Level 14 License \\
Processing & AR7161 680/800MHz \\
Port & 5 \\
\hline
\end{tabular}

Sumber: PT. Telkom Akses (2020) 


\subsection{Spesifikasi Software}

a. Personal Computer (PC)

Tabel 5. Spesifikasi Software Personal Computer

\begin{tabular}{|c|c|}
\hline Needs & Information \\
\hline Operating Sysyem & Ms. Windows XP, Vista, 7, 8, 10. \\
\hline Application & $\begin{array}{l}\text { Microsoft Office 2003, 2007, 2010, } \\
2013 \text {, Winamp, Adobe } \\
\text { reader,antivirus smadav, avast, } \\
\text { Outlook Express dan aplikasi lainya }\end{array}$ \\
\hline
\end{tabular}

b. Server

Tabel 6. Spesifikasi Software Router

\begin{tabular}{ll}
\hline Needs & Information \\
\hline Operating system & $\begin{array}{l}\text { Windows server 2012 , Linux } \\
\text { Clear os }\end{array}$ \\
$\begin{array}{l}\text { Application and antivirus } \\
\text { programs }\end{array}$ & Oracle and ClamAV \\
Application & Winbox, Mozila, Vlc, Ms.Office \\
\hline
\end{tabular}

Sumber: PT. Telkom Akses (2020)

c. Router

Tabel 7. Spesifikasi Software Router

\begin{tabular}{ll}
\hline Needs & Information \\
\hline Operating system & Mikrotik 5.12 \\
\hline
\end{tabular}

Sumber: PT. Telkom Akses (2020) 


\section{Topologi Jaringan Usulan}

Pada topologi jaringan usulan, dimana semua peralatan antara kantor pusat dan cabang saling terhubung dengan adanya perlindungan komunikasi menggunakan IPSec.

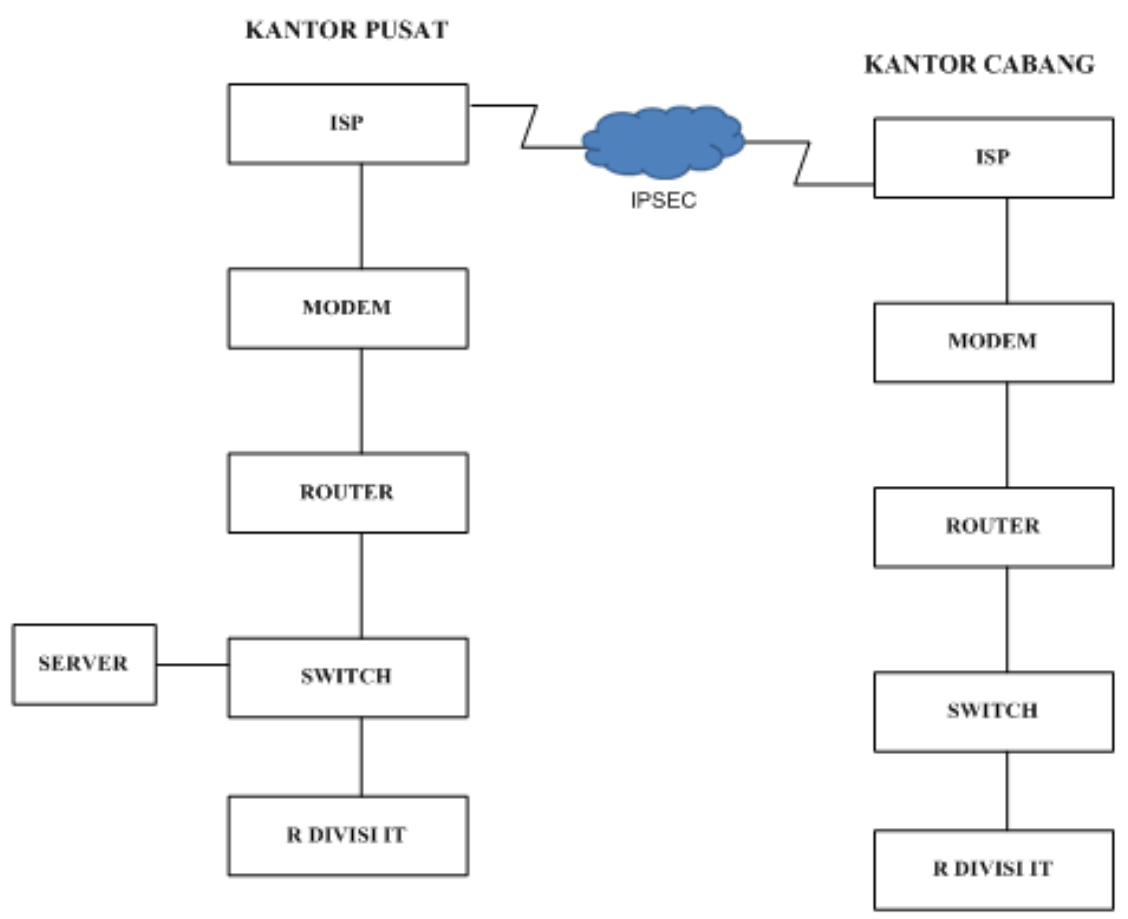

Sumber: PT. Telkom Akses (2020)

Gambar 3. Topologi Jarirngan PT. Telkom Akses

Berdasarkan permasalahan yang ada maka penulis memberikan usulan jaringan untuk mengoptimalkan jaringan yang ada pada PT. Telkom Akses.

\section{Skema Jaringan Ususlan}

Komunikasi antara kantor pusat dan cabang dimana sebelumnya hanya menggunakan jaringan PPTP Tunneling yang rentan terhadap masalah keaaman data sudah diubah menggunakan jaringan VPN IPSEC..

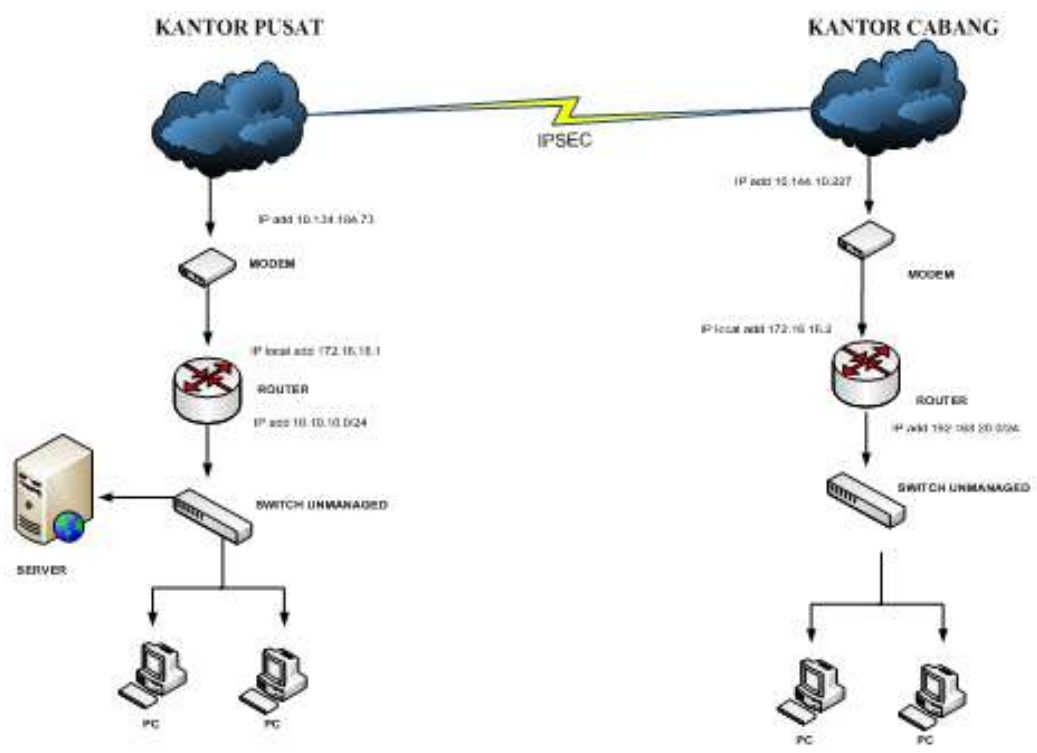

Sumber: PT. Telkom Akses (2020)

Gambar 4. Skema Jaringan Usulan PT. Telkom Akses 
Keterangan dari skema jaringan komputer usulan PT.Telkom Akses adalah sebagai berikut :

1. Tidak adanya penambahan perangkat baru dalam skema jaringan komputer pada PT.Telkom Akses.

2. Terdapat satu router pada masing-masing site yang menjadi pusat dari IPSEC.

3. Perancangan jaringan IPSEC membuat perubahan pada pengiriman data baik dari kantor pusat ke kantor cabang ataupun sebaliknya yang awalnya pengiriman data menggunakan VPN dengan adanya jaringan IPSEC ini menjadikan adanya autentikasi serta enkripsi dalam penghubungan antara site A dan site B .

\section{Keamanan Jaringan}

Keamanan jaringan IPSEC ini menggunakan autentikasi algorithma dan enkripsi algorithma dalam pengiriman data dari site A ke site B agar tidak dapat terdeteksi sehingga pihak yang tidak berhak mengakses dapat masuk ke dalam jaringan IPSEC yang telah dibuat. Pada jaringan ini menggunakan autentikasi algorithma md5 untuk mengamankan secret dan enkripsi algoritma menggunakan 3des dan aes-128cbc serta menggunakan autentikasi method yaitu pre shared key (berdasarkan secret yang dibuat sebelumnya). (Umam \& Roza, 2016)

\section{Manajemen Jaringan}

Manajemen jaringan Wide Area Network (WAN) pada PT. Telkom Akses, penulis menambahkan sebuah jaringan IPSEC untuk melakukan komunikasi dan pertukaran data antara kantor pusat dan kantor cabang. Jaringan IPSEC yang dibuat dapat diakses hanya oleh client yang diberikan akses untuk berkomunikasi menggunakan jaringan IPSEC ini. (Towidjojo, 2016)

Dengan membangun jaringan IPSEC pada PT. Telkom Akses dapat meningkatkan kestabilan pertukaran data, kerahasiaan data menjadi lebih terjamin dengan adanya autentikasi dan enkripsi, mempermudah karyawan mengambil data di kantor pusat apabila sedang berada jauh di luar kantor jika memiliki user untuk mengakses jaringan IPSEC.

\section{Pengujian Jaringan}

Pengujian jaringan IPSEC disimulasikan penulis dengan melakukan pengiriman paket icmp (ping) dari site A ke site B untuk pengujian awal dan untuk pengujian akhir penulis melakukan sharing folder antara site A dan site B pada jaringan yang sudah dibuat.

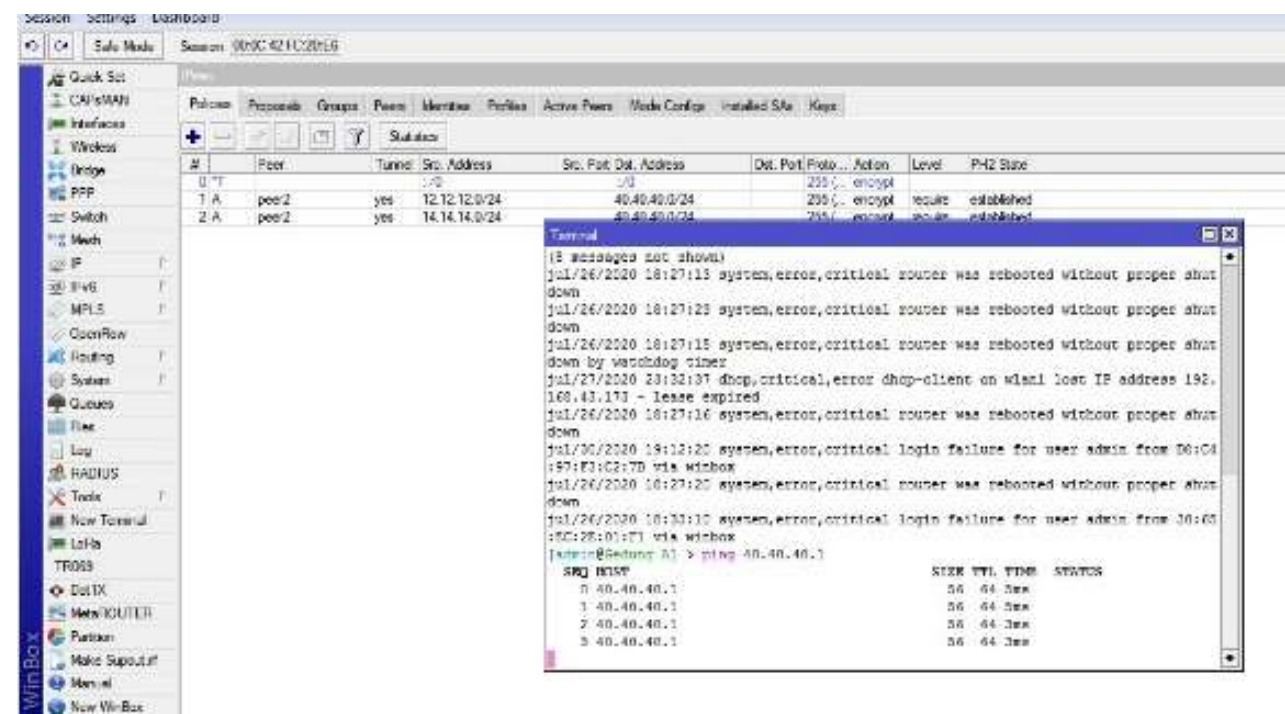

Sumber: PT. Telkom Akses (2020)

Gambar 5. Hasil Pengujian Dari Site A Ke Site B 


\section{KESIMPULAN}

Penulis menyimpulkan dari seluruh pokok bahasan mengenai penerapan jaringang IPSEC PT Telkom Akses. Dengan adanya jaringan IPSEC membuat koneksi lebih stabil dan lebih aman. File dan folder yang dapat dipakai bersama-sama oleh anggota jaringan, juga memudahkan network administrator dalam mengelola jaringan jika terkendala jarak antar site, maka jaringan telah terenkripsi dengan baik dan sudah menggunakan autentikasi untuk menghubungkan antar site.

Adapun saran yang akan diberikan dalam penggunaan jaringan IPSEC ini yaitu dengan mengadakan sosialisasi jaringan kepada network administrator agar dapat mengoperasikan sistem dengan baik dengan menggunakan perangkat yang memadai dan mendukung sistem yang ada, selalu melakukan backup konfigurasi data untuk menghindari terjadinya kehilangan data.

\section{REFERENSI}

AMIK BSI Purwokerto, A. M. L., \& - AMIK BSI Purwokerto, Y. B. (2018). Analisis Sistem Pengelolaan, Pemeliharaan dan Keamanan Jaringan Internet Pada IT Telkom Purwokerto. Evolusi : Jurnal Sains Dan Manajemen, 6(2). https://doi.org/10.31294/evolusi.v6i2.4427

Darma, U. B., Purwanto, T. D., Komputer, T., Vokasi, F., Darma, U. B., Komputer, T., Vokasi, F., \& Darma, U. B. (2018). Implementasi ftp server dengan memanfaatkan vpn mikrotik sebagai keamanan jaringan di bnnp sumsel 1. 48-53.

Hutahaean dan Rohim. (2016). Topologi Jaringan Topologi Jaringan. In Perangkat Keras Jaringan Komputer (p. 110).

Ikhwan, S., \& Amalina, A. (2017). Analisis Jaringan VPN Menggunakan PPTP dan L2TP. JURNAL INFOTEL, 9(3). https://doi.org/10.20895/infotel.v9i3.274

Khasanah, S. N., \& Utami, L. A. (2018). Implementasi Failover Pada Jaringan WAN Berbasis VPN. Jurnal Teknik Informatika STMIK Antar Bangsa, IV(1), 62-66.

Rianto, A. S. (2018). Jaringan Komputer : Konsep Dasar Pengembangan Jaringan dan Keamanan Jaringan. Andi Publisher.

Sulistyanto, A. (2018). Analisa Jaringan Komputer Local Area Network (LAN) Pada Divisi Information System Operation Support PT. Telekomunikasi Indonesia, Tbk Jakarta. https://repository.bsi.ac.id/index.php/repo/viewitem/7814

Towidjojo, R. (2016). Mikrotik Kung Fu. Jasakom.

Umam, C., \& Roza, E. (2016). Perancangan Jaringan Keamanan Virtual Private Network ( VPN ) Siteto Site. Perancangan Jaringan Keamanan Virtual Private Network (VPN)Siteto Site Chairul, 23-30. https://journal.uhamka.ac.id/index.php/teknoka/article/view/335

Watmah, S. (2020). Implementasi VPN Menggunakan Point-To-Point Tunneling Protocol ( PPTP ) Mikrotik Router Pada BPRS Bumi Artha Sampang. 1(1), 6-12. 